\title{
MARKETING
}




\section{IMAGEM DE DESTINO TURÍSTICO: PROPOSIÇÃO DE MODELO HIPOTÉTICO}

TOURIST DESTINATION IMAGE: PROPOSED HYPOTHETICAL MODEL

Lilian Dominguez Santana

Universidade Federal de Minas Gerais

Marlusa de Sevilha Gosling

Universidade Federal de Minas Gerais
Data de submissão: 26 jun. 20 |6. Data de aprovação:

06 fev. 2017. Sistema de avaliação: Double blind review.

Universidade FUMEC / FACE. Prof. Dr. Henrique Cordeiro

Martins. Prof. Dr. Cid Gonçalves Filho.

RESUMO

Imagem de destino é uma temática amplamente debatida em estudos de turismo. Em virtude da complexidade, a formação da imagem de destino é um tema ainda em discussão, e, portanto, com grandes oportunidades de pesquisa. $\mathrm{O}$ objetivo desse estudo é analisar modelos de formação da imagem de destino visando a proposição de um modelo hipotético que contemple desde as relações entre as dimensões da imagem de destino (cognitiva, afetiva, única e global), a influência de fatores externos e internos (familiaridade informativa, experiencial, características sociodemográficas e motivações), até a influência da imagem de destino sobre intenções comportamentais (retorno e recomendação). O estudo traz contribuições para o enriquecimento da literatura com a proposição de um modelo único de formação e influência da imagem de destino.

\section{PALAVRAS-CHAVE}

Formação da Imagem de Destino. Imagem Cognitiva. Imagem Afetiva. Imagem Única. Imagem Global. 


\section{ABSTRACT}

Destination image is a widely debated topic in tourism studies. Due to the complexity, the destination image formation is a matter still under discussion and, therefore, with great opportunities for research. The aim of this study is to analyze the destination image models, in order to propose a hypothetical model that reflects since the relationship between the destination image dimensions (cognitive, emotional, unique and overall), the influence of external factors and internal (information familiarity, experiential, sociodemographic characteristics and motivations), until the destination image influence on behavioral intentions (return and recommendation). The study brings contributions to the enrichment of literature with the proposition of a single model of formation and influence of tourist destination image.

\section{KEYWORDS}

Destination Image Formation. Image Cognitive. Affective Image. Single Image. Overall Image.

\section{INTRODUÇÃO}

A imagem de um destino turístico consiste em uma construção mental que tem por base impressões, crenças e conhecimentos sobre ele (AHMED, I99I; CASTRO; MARTÍN ARMARIO; MARTÍN RUIZ, 2007; DICHTER, 1985; KOTLER et al., 2006). Essa construção ocorre por meio do acúmulo e das modificações de imagens mentais decorrentes da experiência no destino ou formadas a partir de fontes de informações secundárias (AHMED, 199I; CHON, 1991). Além de ser crucial na etapa de seleção entre as diversas opções de destino, a imagem de destino cria e molda as expectativas do turista antes da experiência real. A partir desta, novas imagens são acumuladas, modificadas e resignificadas, influenciando ainda as intenções comportamentais pós-visita (BIGNE; SANCHEZ; SANCHEZ, 200 I; CASTRO; MARTÍN ARMARIO; MARTÍN RUIZ, 2007; CHEN; TSAI, 2007; HALLMANN; ZEHRER; MÜLLER, 20I5; NISCO et al., 20I5; SMITH et al., 20I5). Essa acentuada relevância da imagem de destino leva à preocupação em conhecer os fatores que influenciam sua formação.

A área científica deste estudo corresponde à temática "Imagem de destino turístico", que tem sido amplamente estudada na área do turismo (PIKE, 2002). O foco principal, no entanto, é a análise do processo de formação da imagem, uma das áreas menos pesquisadas, segundo Cherifi et al. (20/4) e Mariussen, Ibenfeldt e Vespestad (2014). Para os propósitos desta pesquisa, modelos relacionados à imagem de destino turístico foram revisados e relacionados também a outros estudos. Perceberam-se lacunas em função tanto de resultados contraditórios quanto da ausência de teste de algumas relações. $O$ objetivo desta pesquisa é, portanto, analisar modelos de formação da imagem de destino visando a proposição de um modelo hipotético que contemple desde as relações entre as dimensões da imagem de 
destino (cognitiva, afetiva, única e global), a influência de fatores externos e internos (familiaridade informativa, experiencial, características sociodemográficas e motivações), até a influência da imagem de destino sobre intenções comportamentais (retorno e recomendação).

De maneira geral, este estudo visa contribuir para o enriquecimento da literatura sobre imagem de destino a partir da compilação de um modelo único de formação e influência da imagem de destino, contemplando as relações entre os antecedentes, as dimensões da imagem de destino e as intenções comportamentais.

\section{Dimensões cognitiva, afetiva, global e única da imagem de destino}

O modelo de formação de imagem proposto por Mccleary e Baloglu (1999) constitui-se em um dos principais modelos de formação da imagem (CHAGAS, 2009; GALLARZA; SAURA; GARCÍA, 2002) e tem sido utilizado como base em diversas pesquisas subsequentes (BEERLI; MARTÍN, 2004; BIGNE; SANCHEZ; SANCHEZ, 200I; CASTRO; MARTÍN ARMARIO; MARTÍN RUIZ, 2007; CHEN; TSAI, 2007; HALLMANN; ZEHRER; MÜLLER, 20I5; LLODRÀ-RIERA et al., 20I5; MARIUSSEN; IBENFELDT; VESPESTAD, 20I4; MOURA; GNOTH; DEANS, 20I5; QU; KIM; IM, 20I I; SUÁREZ; JOSÉ, 20II).

O modelo proposto por Mccleary e Baloglu (1999) (ver Figura I) retrata a imagem global, ou geral, de um destino como aquela antecedida pela avaliação denominada "cognitiva", que consiste no conjunto de crenças e conhecimentos sobre o destino, e pela avaliação afetiva, que se refere aos sentimentos em relação a ele. A imagem global (positiva ou negativa) seria, portanto, uma combinação dos fatores cognitivos e afetivos (BEERLI; MARTíN, 2004). Conforme San Martín e Rodríguez Del Bosque (2008), inicialmente apenas a dimensão

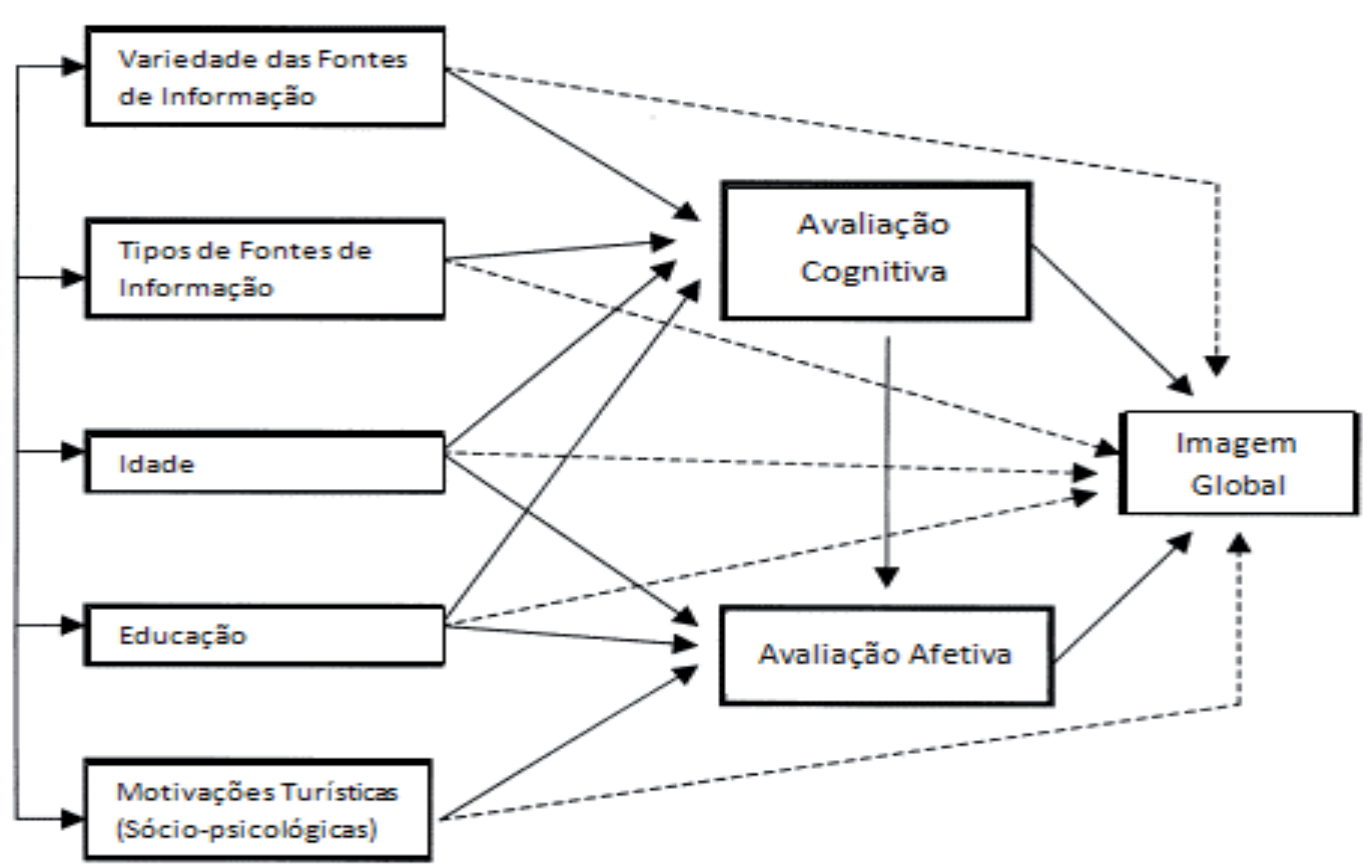

FIGURA 1 - Modelo de formação de imagem de destino proposto por Mccleary e Baloglu (1999) Fonte: Adaptada de Mccleary e Baloglu (1999) 
cognitiva era considera pelos estudos sobre imagem de destino (abordagem cognitiva tradicional). Posteriormente, a natureza cognitivo-afetivo foi proposta e considerada em diversas pesquisas posteriores.

Mccleary e Baloglu (1999) acrescentam que a avaliação afetiva e a cognitiva estão inter-relacionadas, sendo que o conhecimento sobre o destino influencia os sentimentos em relação a ele, bem como a formação da imagem global do destino, que se compõe dos sentimentos e conhecimentos. Isso porque, ainda que exista essa relação de influência entre imagem cognitiva e imagem afetiva, cada componente da imagem tem contribuições únicas para a formação da imagem global (QU; KIM; IM, 20 I I). Tendo por base o modelo proposto por Mccleary e Baloglu (1999), Beerli e Martín (2004) também consideraram como componentes da imagem de destino as dimensões cognitiva, afetiva e global, bem como essa inter-relação entre as dimensões cognitiva e afetiva da imagem de destino (ver Figura 2).
Enquanto as avaliações, ou imagens, denominadas "cognitivas" e "afetivas" são amplamente reconhecidas pela literatura como dimensões da imagem de destino, mais uma dimensão foi incorporada por Qu, Kim e Im (20I I). Os autores, baseando-se no conceito de imagem de marca, propuseram um modelo conceitual (Figura 3), no qual acrescentaram à imagem cognitiva e à imagem afetiva a imagem única no sentido de original, exclusiva ou singular -, como formadora da imagem global de um destino. Isso corrobora com o modelo proposto por Echtner e Ritchie (I99I) em sua dimensão diagonal (ver Figura 5). Diferentemente de Mccleary e Baloglu (1999), Beerli e Martín (2004), Qu, Kim e Im (20II) não analisaram a relação entre as imagens que formam a imagem global.

Para Qu, Kim e Im (20II), associada ao conhecimento (imagem cognitiva) e ao sentimento (imagem afetiva), a percepção de singularidade (imagem única) é determinante para a formação da imagem global de

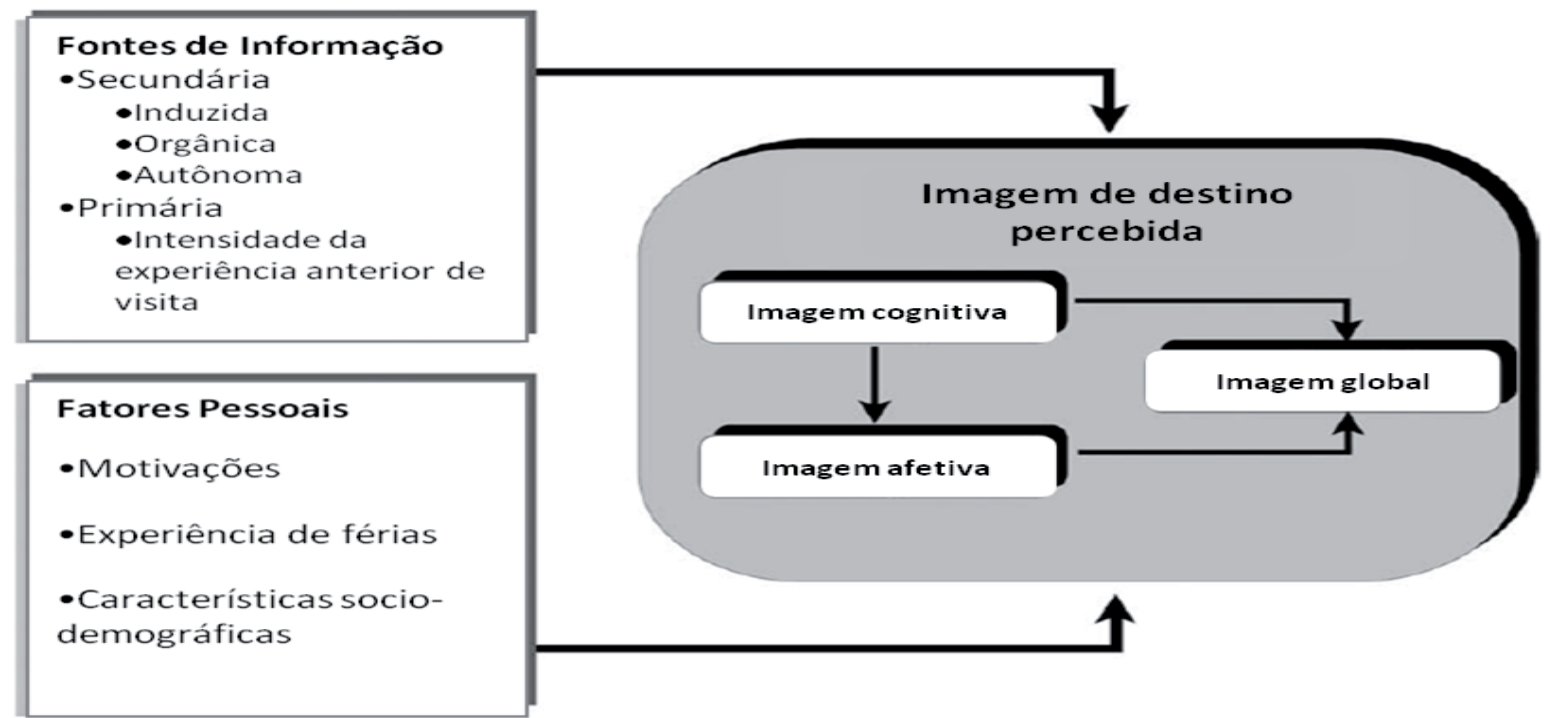

FIGURA 2 - Modelo de formação de imagem de destino proposto por Beerli e Martín (2004) Fonte: Adaptada de Beerli e Martín (2004) 


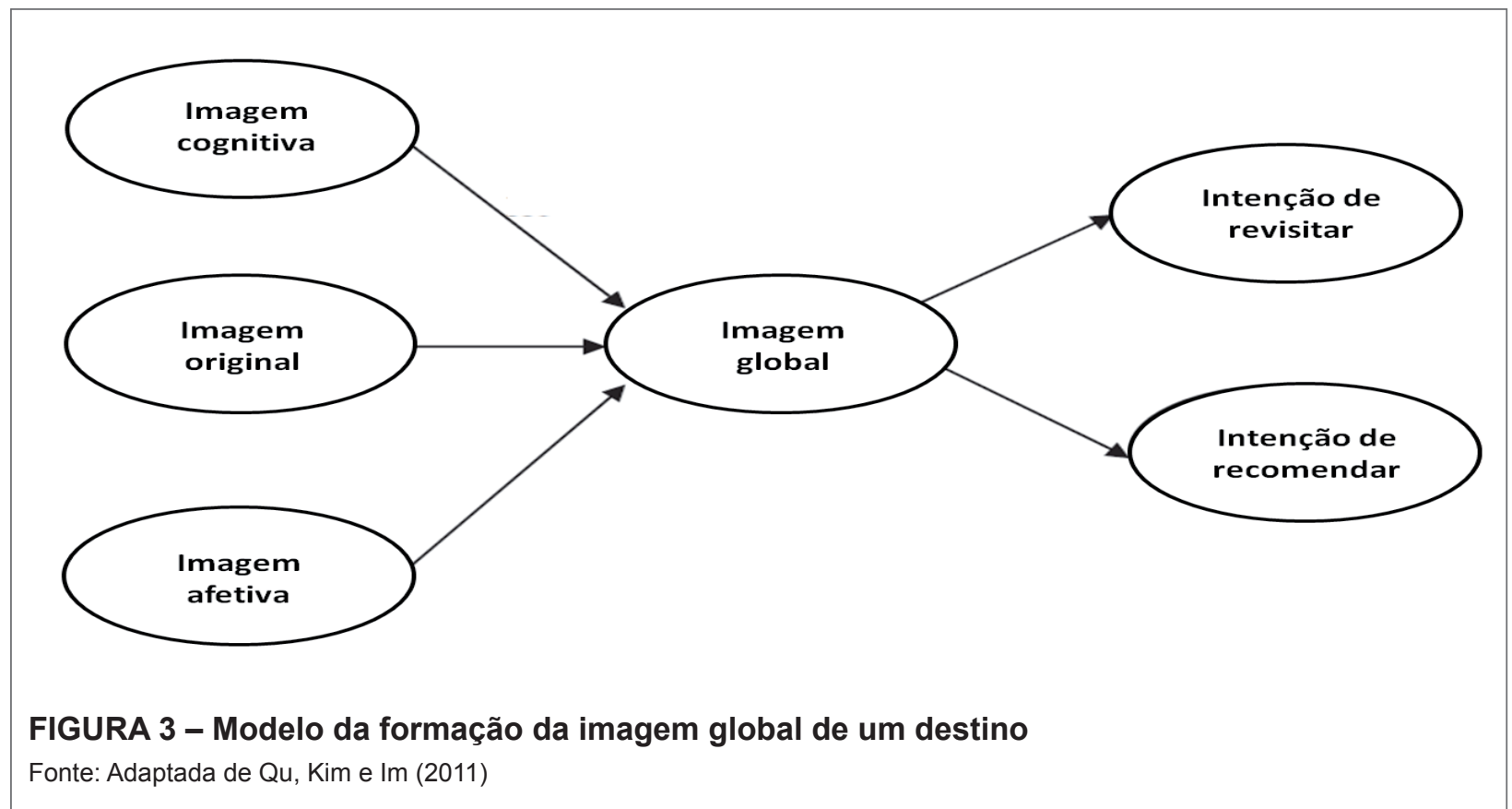

um destino. Justificam que, tendo em vista as vastas opções de destinos turísticos oferecidas aos consumidores com recursos semelhantes, como acomodações de qualidade, bela vista e pessoas amigáveis, nada disso é suficiente para um destino ser mais uma dessas opções. É fundamental que o destino seja identificado como diferenciado e com características únicas nas mentes dos consumidores alvo. $A$ singularidade do destino fornecerá a eles uma razão imperativa para que o destino seja escolhido em detrimento das demais alternativas.

De modo geral, tem-se, portanto, a imagem de destino como sendo composta por quatro dimensões: cognitiva, afetiva, única e global. Uma síntese dos estudos que apresentaram hipóteses relacionadas a essas dimensões constituintes da imagem de destino pode ser conferida no Quadro I.

Todas as hipóteses relacionadas ao fato de a imagem de destino apresentar as dimensões cognitiva, afetiva e única foram confirmadas. Faz-se necessário, no entanto, uma observação quanto ao estudo de
Nisco et al. (20I5), que, apesar de não ter confirmada a influência da imagem afetiva sobre a imagem global, constatou uma influência direta da imagem afetiva sobre intenções comportamentais, bem como a relação hierárquica da imagem cognitiva e da imagem afetiva, sendo a primeira antecedente da segunda. Em relação a análise da dimensão que exerce maior influência sobre a imagem global, os resultados são contraditórios: estudos de Mccleary e Baloglu (1999) apontam a imagem afetiva, ao passo que os de Chagas, Marques Júnior e Duarte (20I3), a imagem cognitiva, rejeitando sua hipótese contrária. Esse resultado corrobora com os de Qu, Kim e Im (20II), que também incluíram a imagem única, a qual apresentou maior influência sobre a imagem global do que a imagem afetiva.

Considerando a inter-relação entre imagem cognitiva e imagem afetiva, a hipótese proposta por Mccleary e Baloglu (1999) e por Nisco et al. (2015) de que a primeira influencia significativamente a segunda foi fortemente apoiada. Para a inter 
QUADRO 1 - Hipóteses de estudos relacionadas às dimensões da imagem de destino

\begin{tabular}{|c|c|c|}
\hline Referência & Hipótese & Resultado \\
\hline \multicolumn{3}{|c|}{ Imagem cognitiva } \\
\hline $\begin{array}{l}\text { (MCCLEARY; BALOGLU, } \\
\text { 1999) }\end{array}$ & $\begin{array}{l}\text { A avaliação da percepção cognitiva influencia } \\
\text { significativamente a imagem global de um destino turístico. }\end{array}$ & $\begin{array}{l}\text { Hipótese moderadamente apoiada } \\
\text { para duas das três dimensões } \\
\text { cognitivas. }\end{array}$ \\
\hline $\begin{array}{l}\text { (SAN MARTÍN; } \\
\text { RODRÍGUEZ DEL } \\
\text { BOSQUE, 2008) }\end{array}$ & $\begin{array}{l}\text { A imagem de destino é formada conjuntamente por } \\
\text { avaliações cognitivas e afetivas do indivíduo do destino } \\
\text { turístico. }\end{array}$ & Hipótese confirmada. \\
\hline (QU; KIM; IM, 2011) & $\begin{array}{l}\text { A imagem cognitiva vai afetar positivamente a imagem } \\
\text { global do visitante de um destino. }\end{array}$ & Hipótese confirmada. \\
\hline (SUÁREZ; JOSÉ, 2011) & $\begin{array}{l}\text { A imagem percebida de um destino turístico se constitui } \\
\text { pela combinação de avaliações cognitivas e afetivas. }\end{array}$ & Hipótese confirmada. \\
\hline $\begin{array}{l}\text { (CHAGAS; MARQUES } \\
\text { JÚNIOR; DUARTE, 2013) }\end{array}$ & $\begin{array}{l}\text { A percepção cognitiva influencia diretamente a formação da } \\
\text { imagem do destino. }\end{array}$ & Hipótese confirmada. \\
\hline (NISCO et al., 2015) & $\begin{array}{l}\text { O componente cognitivo da imagem geral de um país, formado } \\
\text { como resultado da experiência de viagem, tem uma influência } \\
\text { positiva sobre a imagem do país como destino turístico. }\end{array}$ & Hipótese confirmada. \\
\hline \multicolumn{3}{|c|}{ Imagem afetiva } \\
\hline $\begin{array}{l}\text { (MCCLEARY; BALOGLU, } \\
\text { 1999) }\end{array}$ & $\begin{array}{l}\text { Avaliações afetivas influenciam significativamente a } \\
\text { imagem global de um destino turístico. }\end{array}$ & Hipótese fortemente apoiada. \\
\hline $\begin{array}{l}\text { (SAN MARTÍN; } \\
\text { RODRÍGUEZ DEL } \\
\text { BOSQUE, 2008) }\end{array}$ & $\begin{array}{l}\text { A imagem de destino é formada conjuntamente por } \\
\text { avaliações cognitivas e afetivas. }\end{array}$ & Hipótese confirmada. \\
\hline (QU; KIM; IM, 2011) & $\begin{array}{l}\text { A imagem afetiva vai afetar positivamente a imagem global } \\
\text { do visitante de um destino. }\end{array}$ & Hipótese confirmada. \\
\hline (SUÁREZ; JOSÉ, 2011) & $\begin{array}{l}\text { A imagem percebida de um destino turístico se constitui } \\
\text { pela combinação de avaliações cognitivas e afetivas. }\end{array}$ & Hipótese confirmada. \\
\hline \multirow[b]{2}{*}{$\begin{array}{l}\text { (CHAGAS; MARQUES } \\
\text { JÚNIOR; DUARTE, 2013) }\end{array}$} & $\begin{array}{l}\text { A percepção afetiva influencia diretamente a formação da } \\
\text { imagem do destino. }\end{array}$ & Hipótese confirmada. \\
\hline & $\begin{array}{l}\text { A percepção afetiva possui maior influência na formação da } \\
\text { imagem que a cognitiva. }\end{array}$ & $\begin{array}{l}\text { Hipótese rejeitada. As avaliações } \\
\text { cognitivas exercem maior influência } \\
\text { para a formação da imagem de } \\
\text { destino. }\end{array}$ \\
\hline (NISCO et al., 2015) & $\begin{array}{l}\text { O componente afetivo da imagem geral de um país, } \\
\text { formado como resultado da experiência de viagem, tem } \\
\text { uma influência positiva sobre a imagem do país como } \\
\text { destino turístico. }\end{array}$ & $\begin{array}{l}\text { Hipótese não confirmada: a imagem } \\
\text { afetiva não afetou a imagem de } \\
\text { destino pós-viagem. }\end{array}$ \\
\hline \multicolumn{3}{|c|}{ Inter-relação entre imagem cognitiva e afetiva } \\
\hline $\begin{array}{l}\text { (MCCLEARY; BALOGLU, } \\
\text { 1999) }\end{array}$ & $\begin{array}{l}\text { A avaliação da percepção cognitiva influencia significativamente } \\
\text { as avaliações afetivas de um destino turístico. }\end{array}$ & A hipótese foi fortemente apoiada. \\
\hline (NISCO et al., 2015) & $\begin{array}{l}\text { O componente cognitivo da imagem geral de um país, } \\
\text { formada como resultado da experiência de viagem, tem um } \\
\text { efeito positivo sobre o componente afetivo. }\end{array}$ & Hipótese confirmada. \\
\hline \multicolumn{3}{|c|}{ Imagem única } \\
\hline (QU; KIM; IM, 2011) & $\begin{array}{l}\text { A imagem única vai afetar positivamente a imagem global } \\
\text { do visitante de um destino. }\end{array}$ & $\begin{array}{l}\text { Hipótese confirmada. A imagem } \\
\text { cognitiva tem o efeito mais forte } \\
\text { sobre a imagem global, seguida pela } \\
\text { imagem única e imagem afetiva, } \\
\text { respectivamente. }\end{array}$ \\
\hline
\end{tabular}

Fonte: Elaborado pelo autor 
-relação entre imagem cognitiva e imagem única não há parâmetros, uma vez que $\mathrm{Qu}$, Kim e Im (20II) não fizeram avaliações nesse sentido, porém recomendaram para estudos futuros a análise das relações entre as dimensões da imagem de destino. Apesar de ainda não testado em estudos anteriores, é possível considerar que, assim como o conhecimento (imagem cognitiva) influencia os sentimentos (imagem afetiva) em relação a um destino, o conhecimento também exerça influência sobre a percepção de singularidade do mesmo (imagem única).

Analisando as relações entre as dimensões da imagem de destino, é possível também considerar que essa percepção de singularidade (imagem única) exerça influência sobre a imagem afetiva, ou sentimentos em relação ao destino, apesar de isso não ter sido verificado em estudos anteriores. Conforme Kim (20I4), os viajantes desejam experimentar algo novo, e por isso têm forte tendência a escolher destinos em que a cultura e o estilo de vida são diferentes. A busca por novidade, inclusive, tendo por base os estudos de Chandralal e Valenzuela (2013), é apresentada pelo autor como uma das dimensões que tornam uma experiência de turismo memorável. Estudos recentes avaliaram os efeitos dos valores culturais em websites de destinos turísticos sobre a disponibilidade de usuários para viajar e sobre a imagem de destino (MOURA; GNOTH; DEANS, 20I5). Constatou-se que sites de destinos com uma representação de valores culturais incongruentes para um público-alvo geram uma imagem de destino mais positiva e maior disponibilidade para viagens. Como ressaltado por Moura, Gnoth e Deans (2015), alta congruência cultural pode levar ao té- dio, por reduzir os elementos de novidade em relação ao destino.

Analisando a escala amplamente utilizada pelos autores (MCCLEARY; BALOGLU, I999; QU; KIM; IM, 20II; SUÁREZ; JOSÉ, 20I I; YACOUT; HEFNY, 20I5) para mensuração da imagem afetiva (estimulante / entediante, agradável / desagradável, empolgante / chato, relaxante / estressante), é possível verificar que duas das quatro escalas fazem referência à presença ou não desse sentimento de tédio (destino estimulante/entediante e destino empolgante/ chato). Considerado a afirmação de Moura, Gnoth e Deans (20I5) e tendo em vista que a imagem única representa os elementos que distinguem um destino de outros, é possível considerar que uma baixa percepção de singularidade de um destino pode acarretar em uma imagem afetiva mais negativa, em virtude da falta de identificação de diferenciais desse destino em relação a outros, podendo, desse modo, ser considerado chato ou entediante.

A partir do exposto, formularam-se as seguintes hipóteses de pesquisa:

Hipótese I: A imagem cognitiva influencia positivamente a imagem global.

Hipótese 2: A imagem afetiva influencia positivamente a imagem global.

Hipótese 3: A imagem única influencia positivamente a imagem global.

Hipótese 4: $A$ imagem cognitiva influencia positivamente a imagem única.

Hipótese 5: A imagem cognitiva influencia positivamente a imagem afetiva.

Hipótese 6: A imagem única influencia positivamente a imagem afetiva.

\section{Antecedentes da imagem de destino}

Interessados em identificar o que influencia o desenvolvimento ou a formação da 
imagem de um destino, Mccleary e Baloglu (1999) consideraram como antecedentes da imagem duas forças principais: fatores de estímulos (fontes de informação) e os fatores pessoais (características sociodemográficas e motivações turísticas). Esses fatores, segundo os autores, são responsáveis por formar a imagem de um destino.

Tem-se, portanto, como antecedentes da imagem de destino as fontes de informação (comumente classificadas como fontes secundárias e fontes primárias), as características sociodemográficas e as motivações turísticas. A nomenclatura fonte secundária e fonte primária decorre da distinção feita por Phelps (1986) para as duas formas de imagem: a secundária se refere às impressões sobre um lugar; e a primária é formada a partir da experiência no destino. Trata-se do que Baloglu (200I) denomina de familiaridade informativa e familiaridade experiencial, respectivamente.

\section{Familiaridade com o destino (informativa e experiencial)}

Conforme Jacobsen e Munar (2012), a busca de informações é uma etapa crucial para os turistas na escolha de um destino. Esse comportamento está relacionado à necessidade de minimizar os riscos e as incertezas diante da aquisição de produtos caros ou complexos, como o planejamento de férias. Como ressaltado por Tasci e Gartner (2007), antes da visitação real ao destino as pessoas se baseiam em indicações visuais apresentadas sobre o destino. Para tanto, costumam combinar diversas fontes de informação disponíveis, tais como: guias e materiais específicos sobre o destino, meios de comunicação, empresas de viagens, conhecimento repassado diretamente por conhecidos e familiares, infor- mações a partir de redes sociais e blogs eletrônicos ou informações decorrentes da própria experiência no destino.

O processo de busca de informação pelo consumidor, porém, ainda é um tema controverso. Há autores que defendem que o conhecimento prévio é um importante antecedente para a busca de informações, ao passo que outros têm relatado uma relação inversa, na qual quanto maior - conhecimento prévio menor a busca de informações (AWASTHY; BANERJEE; BANERJEE, 20I2). Por exemplo, Jacobsen e Munar (20I2) colocam que, caracteristicamente, visitantes de retorno parecem confiar muito mais em experiências passadas do que escolher coletar mais informações sobre destinos já visitados. De modo geral, segundo os autores, um turista busca informações de destinos dos quais tenha um prévio conhecimento (ou prévia imagem). Porém, quanto maior seu conhecimento sobre determinado destino, menor a necessidade de buscar informações sobre ele. Outro exemplo, os estudos de Beerli e Martín (2004), apesar de terem como foco a imagem de destino para visitantes de primeira visita comparativamente a visitantes que retornaram ao destino pesquisado, investigaram a influência das fontes de informação apenas sobre os visitantes de primeira visita por considerarem que as fontes de informação secundárias são consultadas apenas para a primeira visita a um destino.

É importante destacar, entretanto, que a busca por informações pode ocorrer mesmo quando não há um benefício funcional óbvio, podendo ser motivada pelo desejo de antecipação (PARRINELLO, 1993). Awasthy, Banerjee e Banerjee (20I2) concluem que uma explicação para a relação conflitan- 
te entre conhecimento prévio e busca de informações inclui: que um conhecimento prévio suficiente limita a necessidade por informações adicionais a partir de fontes externas; e que consumidores que possuem conhecimento prévio podem realizar pesquisas mais eficientes buscando informações consideradas importantes e úteis.

De modo geral, as variadas fontes de informação podem ser classificadas em três tipos: induzidas, autônomas e orgânicas, conforme Beerli e Martín (2004), citando os estudos de Gartner (1994). Fontes induzidas estão relacionadas à intenção específica de promover um destino, incluindo folhetos turísticos, brochuras de operadores turísticos, campanhas publicitárias de mídia de massa, funcionários de agências de viagens e sites de operadores turísticos. Diferentemente, fontes orgânicas não visam a promoção de um destino, mas, envolvem informações dadas por amigos e parentes, a partir do conhecimento ou experiência (BEERLI; MARTÍN, 2004). Tendo por base a escala utilizada por Jacobsen e Munar (20I2), as fontes orgânicas podem ainda ser subdivididas em fontes a partir de conhecidos (parentes e amigos) e, a partir de desconhecidos (blogs e sites de avaliação). As fontes autônomas incluem guias, notícias, artigos, relatórios, documentários e programas sobre o destino na mídia (TASCl; GARTNER, 2007).

Enquanto os não visitantes desfrutam apenas de fontes de informações secundárias e da sua imaginação, visitantes apresentam informações armazenadas na memória (ANKOMAH; CROMPTON, 1992). Como colocado por Petrocchi (2004, p. 43),“o turista só efetivamente formará uma opinião sobre o destino quando realizar a experiência da viagem". Antes do contato real, o destino constitui-se em uma promessa e em um conjunto de expectativas, muitas vezes, irreais sobre o destino (TASCl; GARTNER, 2007).A partir do contato com o destino, forma-se o que Chagas (2009) denomina de "imagem complexa”, baseada na experimentação do destino.

A visita constitui-se, assim, em fonte primária de informação para o turista. Os estudos realizados por Smith et al. (2015) concentraram-se na influência das fontes de informação primárias na formação da imagem de destino. Eles verificaram a natureza dinâmica e evolutiva da imagem, que oscila durante toda a experiência de viagem. Chon (1991) realizou pesquisas para analisar a forma como a imagem de um destino turístico e as percepções turísticas são modificadas ao longo dos estágios de viagem para o destino e seu regresso. Os resultados indicaram diferenças reais entre as percepções daqueles que retornavam do destino e as daqueles que chegavam ao destino pela primeira vez e para diferentes fatores, o que mostra a relevância das fontes primárias para a formação da imagem de destino. Explica Gândara (2008, p. 2), "quanto maior e melhor informação disponha o turista com relação ao destino, mais a imagem que este terá do referido destino corresponderá à realidade". Ocorre que quanto mais os indivíduos frequentam um destino mais preciso o seu conhecimento e, portanto, mais precisa sua imagem do destino (ANKOMAH; CROMPTON, 1992).

As fontes de informação foram apresentadas, até então, a partir de dois prismas: fontes secundárias e fontes primárias. Baloglu (200I), porém, resume as fontes de informação secundárias e primárias em uma única dimensão, denominada, "familiaridade", que para ele corresponde a 
um composto de quantidade de informação utilizada (familiaridade informativa) e experiência anterior no destino (familiaridade experiencial). Segundo o autor, a familiaridade com um destino pode ser mensurada e operacionalizada a partir de dois indicadores: familiaridade informativa, medida a partir da quantidade de informação utilizada; e familiaridade experiencial, a partir da existência ou não da visita ao destino. Tendo por base os estudos de $\mathrm{Ba}$ loglu (200I) é possível assumir o termo familiaridade em suas duas dimensões: informativa e experiencial. Associando aos estudos de Mccleary e Baloglu (1999) e Beerli e Martín (2004), ter-se-ia a familiaridade da seguinte forma:

a) Informativa: a partir do número de fontes de informação utilizadas (BALOGLU, 200I; MCCLEARY; BALOGLU, 1999) e de sua influência (BEERLI; MARTÍN, 2004; MCCLEARY; BALOGLU, 1999);

b) Experiencial: a partir do número de visitas ao destino (BALOGLU, 200I; BEERLI; MARTÍN, 2004) e do número de atrativos turísticos visitados (BEERLI; MARTíN, 2004).

Em relação à influência da familiaridade sobre a imagem de destino, o Quadro 2 apresenta uma síntese dos estudos que apresentaram hipóteses relacionadas e os resultados, confirmação ou não dessas hipóteses.

Enquanto os estudos de Baloglu (200I) confirmaram uma associação significativa e positiva (quanto maior a familiaridade mais positiva a imagem do destino pesquisado), Beerli e Martín (2004), que tinham por hipótese que o número de visitas ao destino e o número de locais de interesse visitados influenciavam significativamente a dimensão cognitiva da imagem de destino, identificaram que quanto maior a repetição de visitas pior a avaliação de aspectos como limpeza, segurança pessoal, hospitalidade e simpatia dos moradores (apenas esses aspectos associados às dimensões social e ambiental apresentaram relação significativa). Petrocchi (2004, p. 22) reforça que "progressivamente, o turista torna-se mais exigente, com expectativas ampliadas e níveis de tolerância reduzidos". Já em relação ao número de locais visitados, na pesquisa de Beerli e Martín (2004), a relação foi positiva: quanto maior o número de atrativos turísticos visitados mais positiva a imagem cognitiva.

Em relação à quantidade de fontes de informação utilizadas, Mccleary e Baloglu (1999) obtiveram apoio parcial para esta hipótese, considerando que a relação entre a quantidade de fonte de informação e a dimensão cognitiva foi positiva e significativamente relacionada a 3 dos 14 indicadores de imagem cognitiva utilizados pelos autores. Os estudos de Beerli e Martín (2004) revelaram: todas as fontes orgânicas e autônomas apresentam relação causal significativa; os agentes autônomos influenciam positivamente os aspectos da infraestrutura geral e turística; e as fontes orgânicas (amigos e familiares) influenciam positivamente a atmosfera e negativamente os aspectos sociais e ambientais, diferentemente de Mccleary e Baloglu (1999). Já em relação às fontes induzidas, com exceção dos funcionários de agências de viagem, foi verificado que apresentam pouca influência sobre a imagem de destino.

Como já discutido, diferentemente dos estudos de Beerli e Martín (2004) e tendo por base as considerações de Awasthy, Banerjee e Banerjee (20I2), a influência das 
QUADRO 2 - Hipóteses de estudos relacionadas à familiaridade

\begin{tabular}{|c|c|c|}
\hline Referência & Hipótese & Resultado \\
\hline \multicolumn{3}{|c|}{ Familiaridade informativa } \\
\hline $\begin{array}{l}\text { (BALOGLU, } \\
\text { 2001) }\end{array}$ & $\begin{array}{l}\text { A familiaridade exerce influência } \\
\text { significativa sobre a imagem de } \\
\text { destino. }\end{array}$ & $\begin{array}{l}\text { O grupo com baixa familiaridade utilizou principalmente fontes de } \\
\text { informação comerciais, tais como brochuras / guias de viagem, anúncios, } \\
\text { operadores turísticos e agentes de viagem. Os grupos de alta e média } \\
\text { familiaridade foram expostos a fontes comerciais, mas também a fontes } \\
\text { não comerciais, como artigos/notícias, livros/filmes e boca a boca. } \\
\text { Quanto maior a familiaridade, mais positiva a imagem do destino. }\end{array}$ \\
\hline \multirow{2}{*}{$\begin{array}{l}\text { (MCCLEARY; } \\
\text { BALOGLU, } \\
\text { 1999) }\end{array}$} & $\begin{array}{l}\text { A variedade (quantidade) das fontes } \\
\text { de informação utilizadas influencia } \\
\text { significativamente as avaliações } \\
\text { cognitivas. }\end{array}$ & $\begin{array}{l}\text { A hipótese foi moderadamente confirmada: a variedade de fontes de } \\
\text { informação foi positivamente e significativamente relacionada a 3, dos } \\
14 \text { indicadores das avaliações cognitivas. }\end{array}$ \\
\hline & $\begin{array}{l}\text { O tipo de fontes de } \\
\text { informação utilizado influencia } \\
\text { significativamente as avaliações } \\
\text { cognitivas. }\end{array}$ & $\begin{array}{l}\text { A hipótese foi moderadamente confirmada: o boca a boca foi } \\
\text { positivamente e significativamente relacionado a } 3 \text { dos } 14 \text { indicadores } \\
\text { das avaliações cognitivas. Os anúncios foram positivamente e } \\
\text { significativamente relacionados a um indicador das avaliações } \\
\text { cognitivas. Os outros dois fatores não foram significativos. }\end{array}$ \\
\hline \multirow{2}{*}{$\begin{array}{l}\text { (BEERLI; } \\
\text { MARTÍN, 2004) }\end{array}$} & $\begin{array}{l}\text { A importância atribuída a fontes } \\
\text { secundárias induzidas de } \\
\text { informação utilizadas pelos turistas } \\
\text { de primeira viagem influencia } \\
\text { significativamente o componente } \\
\text { cognitivo da imagem percebida. }\end{array}$ & $\begin{array}{l}\text { Com exceção de funcionários de agências de viagens, as fontes } \\
\text { induzidas têm pouca influência na imagem pós-visita formada por } \\
\text { turistas. }\end{array}$ \\
\hline & $\begin{array}{l}\text { A importância atribuída a fontes } \\
\text { secundárias orgânicas e autônomas } \\
\text { de informação utilizada por turistas } \\
\text { de primeira viagem influencia } \\
\text { significativamente o componente } \\
\text { cognitivo da imagem percebida. }\end{array}$ & $\begin{array}{l}\text { Em grau moderado, verificou-se que as fontes de informação orgânica } \\
\text { e autônoma influenciam significativamente o componente cognitivo da } \\
\text { imagem percebida (cada fonte relacionou-se com pelo menos um ou } \\
\text { dois fatores cognitivos). }\end{array}$ \\
\hline $\begin{array}{l}\text { (CHAGAS; } \\
\text { MARQUES } \\
\text { JÚNIOR; } \\
\text { DUARTE, 2013) }\end{array}$ & $\begin{array}{l}\text { A imagem do destino é diretamente } \\
\text { influenciada pelas fontes de } \\
\text { informação. }\end{array}$ & $\begin{array}{l}\text { A hipótese foi rejeitada para a relação direta entre as fontes de informação } \\
\text { e a imagem de destino. Os autores sugerem que estudos devam ser } \\
\text { realizados com um mediador, como as motivações ou as dimensões } \\
\text { cognitiva e afetiva entre as fontes de informação e a imagem global. }\end{array}$ \\
\hline $\begin{array}{l}\text { (YACOUT; } \\
\text { HEFNY, 2015) }\end{array}$ & $\begin{array}{l}\text { Os tipos de informação utilizados } \\
\text { estão associados com componentes } \\
\text { cognitivos e afetivos da imagem de } \\
\text { destino. }\end{array}$ & $\begin{array}{l}\text { Hipótese parcialmente confirmada: o modelo foi significativo para a } \\
\text { imagem afetiva e não para a imagem cognitiva. Analisando cada fonte } \\
\text { de informação, a internet foi significativamente relacionada com a } \\
\text { imagem cognitiva; a agência de viagem e experiência anterior foram } \\
\text { significativamente relacionadas à imagem afetiva. O uso de amigos foi } \\
\text { associado à imagem afetiva, porém, a associação não foi significativa. }\end{array}$ \\
\hline \multicolumn{3}{|c|}{ Familiaridade Experiencial } \\
\hline $\begin{array}{l}\text { (BALOGLU, } \\
\text { 2001) }\end{array}$ & $\begin{array}{l}\text { A familiaridade exerce influência } \\
\text { significativa sobre a Imagem de } \\
\text { destino. }\end{array}$ & $\begin{array}{l}\text { O grupo com baixa familiaridade utilizou principalmente fontes de } \\
\text { informação comerciais, tais como brochuras / guias de viagem, anúncios, } \\
\text { operadores turísticos e agentes de viagem. Os grupos de alta e média } \\
\text { familiaridade foram expostos a fontes comerciais, mas também a fontes } \\
\text { não comerciais, como artigos/notícias, livros/filmes e boca a boca. } \\
\text { Quanto maior a familiaridade mais positiva a imagem do destino. }\end{array}$ \\
\hline $\begin{array}{l}\text { (BEERLI; } \\
\text { MARTÍN, 2004) }\end{array}$ & $\begin{array}{l}\text { A experiência dos turistas de primeira } \\
\text { viagem, dependendo do número de } \\
\text { locais de interesse visitados durante a } \\
\text { estadia, influencia significativamente } \\
\text { o componente cognitivo da imagem } \\
\text { percebida. }\end{array}$ & $\begin{array}{l}\text { Hipótese parcialmente confirmada: a experiência de turistas de primeira } \\
\text { viagem, expressa a partir do número de locais de interesse visitados } \\
\text { influencia significativamente o componente cognitivo. Foi encontrada } \\
\text { relação positiva e significativa para as dimensões cognitivas: recursos } \\
\text { naturais e culturais. }\end{array}$ \\
\hline $\begin{array}{l}\text { (BEERLI; } \\
\text { MARTÍN, 2004) }\end{array}$ & $\begin{array}{l}\text { A experiência de turistas de repetição, } \\
\text { dependendo do número de visitas } \\
\text { anteriores e do número de locais } \\
\text { de interesse visitados, influencia } \\
\text { significativamente o componente } \\
\text { cognitivo da imagem percebida. }\end{array}$ & $\begin{array}{l}\text { Hipótese parcialmente confirmada: a experiência de turistas de repetição, } \\
\text { expressa a partir do número de locais de interesse visitados influencia } \\
\text { significativamente o componente cognitivo. Também foi encontrada } \\
\text { relação positiva e significativa para as dimensões cognitivas: recursos } \\
\text { naturais e culturais. Em relação à quantidade de visitas anteriores, a } \\
\text { relação foi significativa e negativa para os aspectos sociais e ambientais. }\end{array}$ \\
\hline
\end{tabular}

Fonte: Dados da pesquisa 
fontes de informação sobre a imagem de destino pode ser avaliada para visitantes, independentemente do número de visitas, considerando que estes, assim como os visitantes primeira visita, também se utilizam dessas fontes, mesmo que a partir de buscas mais eficientes.

Nos estudos de Yacout e Hefny (20 I5) o modelo foi significativo para a imagem afetiva e não para a imagem cognitiva. Como destacado por Mccleary e Baloglu (1999), apesar de não terem, por falta de apoio da literatura, avaliado a influência da variedade e dos tipos de fontes de informação sobre a imagem afetiva, a partir de uma matriz de correlação, essa relação foi significativa.

Para Yacout e Hefny (2015) a influência da fonte de informação experiência anterior sobre a imagem afetiva foi confirmada. Os autores basearam-se em Beerli e Martín (2004), que consideraram em seu estudo o acúmulo de experiências anteriores de viagem a lazer como fonte influenciadora da formação da imagem para turistas de repetição. Esta hipótese foi moderadamente confirmada. É interessante destacar que em suas hipóteses os autores consideraram que a influência desse acúmulo de experiência em viagens está relacionada tanto a imagem cognitiva quanto à imagem afetiva. Assim, parece lógico supor que, em se tratando da experiência anterior no destino pesquisado, essa relação também possa ser significativa considerando a imagem afetiva. Ao serem expostos às diferentes dimensões do destino quando da visita real, o conhecimento (imagem cognitiva) e os sentimentos (imagem afetiva) em relação ao destino podem ser influenciados a partir dos diversos atrativos visitados, do clima, da atmosfera do local, da receptividade, enfim, do contato real com o destino. Pode- se supor, ainda, de maneira análoga, que a percepção de singularidade (imagem única) também seja influenciada pela experiência anterior no destino.

A partir do exposto e tendo em vista que existem resultados conflitantes em relação a ser positiva ou negativa a influência de alguns aspectos, formularam-se as seguintes hipóteses:

Hipótese 7: A familiaridade informativa (quantidade e grau de influência) influencia significativamente as imagens cognitiva, afetiva e única.

Hipótese 8: A familiaridade experiencial (número de visitas e de atrativos visitados) influencia significativamente as imagens cognitiva, afetiva e única.

Considerando a inclusão da dimensão única da imagem de destino, as relações previstas para as imagens cognitiva e afetiva poderão ser avaliadas também considerando a imagem única.

\section{Características sociodemográficas}

Além das fontes de informação, as características sociodemográficas dos consumidores também são determinantes para a formação da imagem de destino (BEERLI; MARTÍN, 2004; MCCLEARY; BALOGLU, 1999; TASCI; GARTNER, 2007). Aspectos como idade, escolaridade, sexo e classe social podem exercer forte influência sobre a imagem que um indivíduo tem de um destino. Conforme Ahmed (1991), as pessoas respondem a vários componentes da imagem de um destino de forma diferente. Assim como os indivíduos diferem em termos de experiências de vida, um mesmo lugar pode ser percebido de forma diferente por pessoas diferentes.

Em relação à influência das características sociodemográficas sobre a imagem de 
destino, o Quadro 3 apresenta uma síntese dos estudos que apresentaram hipóteses relacionadas e os resultados, confirmação ou não dessas hipóteses.

Alguns resultados apresentaram-se contraditórios: em relação à idade, tanto nos estudos de Mccleary e Baloglu (1999) quanto nos estudos de Beerli e Martín (2004) verificou-se relação apenas com a imagem cognitiva, porém enquanto a primeira relação demonstra-se negativa (quanto maior a idade pior a imagem) a segunda apresentase positiva (quanto maior a idade melhor a imagem). Em relação ao nível de educação, enquanto nos estudos de Mccleary e Baloglu (1999) essa característica confirmou-se

QUADRO 3 - Hipóteses de estudos relacionadas às características sociodemográficas

\begin{tabular}{|c|c|c|}
\hline Referência & Hipótese & Resultado \\
\hline \multicolumn{3}{|c|}{ Características sociodemográficas } \\
\hline \multirow{2}{*}{$\begin{array}{l}\text { (MCCLEARY; } \\
\text { BALOGLU, 1999) }\end{array}$} & $\begin{array}{l}\text { A idade dos turistas influencia } \\
\text { significativamente suas avaliações } \\
\text { perceptivas / cognitivas e afetivas } \\
\text { dos destinos. }\end{array}$ & $\begin{array}{l}\text { Apenas a relação entre idade e imagem cognitiva foi significativa e } \\
\text { negativa para duas das três dimensões cognitivas propostas pelos } \\
\text { autores. Não foi significativa para a imagem afetiva. }\end{array}$ \\
\hline & $\begin{array}{l}\text { O nível de educação dos turistas } \\
\text { influencia significativamente suas } \\
\text { avaliações perceptivas / cognitivas } \\
\text { e afetivas dos destinos. }\end{array}$ & $\begin{array}{l}\text { Apoio moderado. Relação significativa entre nível de educação e } \\
\text { imagem cognitiva apenas para uma dimensão e negativa. Não foi } \\
\text { significativa para a imagem afetiva. }\end{array}$ \\
\hline \multirow{3}{*}{$\begin{array}{l}\text { (BEERLI; } \\
\text { MARTÍN, 2004) }\end{array}$} & $\begin{array}{l}\text { O sexo influencia significativamente } \\
\text { os componentes cognitivos e } \\
\text { afetivos da imagem percebida. }\end{array}$ & $\begin{array}{l}\text { Confirmada parcialmente: há uma relação estatisticamente significativa } \\
\text { entre sexo e os fatores da imagem cognitiva relacionada com as } \\
\text { infraestruturas gerais e turísticas (turistas primeira visita) e com o } \\
\text { fator referente ao sol e praia da dimensão cognitiva para os visitantes } \\
\text { retorno. Existe uma relação significativa com a dimensão afetiva, na } \\
\text { medida em que as mulheres tendem a avaliar de forma mais favorável } \\
\text { do que os homens o destino. }\end{array}$ \\
\hline & $\begin{array}{l}\text { A idade influencia } \\
\text { significativamente os componentes } \\
\text { cognitivos e afetivos da imagem } \\
\text { percebida. }\end{array}$ & $\begin{array}{l}\text { Hipótese parcialmente confirmada: influência significativa sobre } \\
\text { a dimensão cognitiva do ambiente natural e social, tanto para } \\
\text { marinheiros de primeira viagem quanto para repetidores, com os } \\
\text { turistas mais velhos geralmente fazendo uma avaliação mais positiva } \\
\text { dessa dimensão da imagem. }\end{array}$ \\
\hline & $\begin{array}{l}\text { O nível de escolaridade influencia } \\
\text { significativamente os componentes } \\
\text { cognitivos e afetivos da imagem } \\
\text { percebida. }\end{array}$ & $\begin{array}{l}\text { Hipótese confirmada parcialmente: só tem efeito significativo sobre a } \\
\text { dimensão afetiva com os níveis mais elevados de educação refletidos } \\
\text { por avaliações mais baixas desta dimensão da imagem. }\end{array}$ \\
\hline $\begin{array}{l}\text { (BEERLI; } \\
\text { MARTÍN, 2004) }\end{array}$ & $\begin{array}{l}\text { A classe social influencia } \\
\text { significativamente os componentes } \\
\text { cognitivos e afetivos da imagem } \\
\text { percebida. }\end{array}$ & $\begin{array}{l}\text { Hipótese confirmada parcialmente: a classe social dos turistas de } \\
\text { primeira viagem tem uma relação significativa com o fator de imagem } \\
\text { cognitiva definida como recursos naturais e culturais; quanto maior } \\
\text { a classe social, menor a pontuação dada aos recursos naturais e } \\
\text { culturais do destino. No caso de turistas de repetição, não há relações } \\
\text { estatisticamente significativas em qualquer das dimensões. }\end{array}$ \\
\hline $\begin{array}{l}\text { (YACOUT; } \\
\text { HEFNY, 2015) }\end{array}$ & $\begin{array}{l}\text { As características demográficas } \\
\text { (idade e renda) estão associadas } \\
\text { com componentes cognitivos e } \\
\text { afetivos da imagem de destino. }\end{array}$ & $\begin{array}{l}\text { O modelo global foi significativo para a imagem cognitiva, mas não } \\
\text { para a imagem afetiva. }\end{array}$ \\
\hline
\end{tabular}

Fonte: Dados da pesquisa 
apenas para a imagem cognitiva, nos estudos de Beerli e Martín (2004) ela está relacionada apenas para a imagem afetiva, ambas as relações apresentaram-se negativas. Em relação ao sexo, na pesquisa de Beerli e Martín (2004) a relação foi confirmada para aspectos das imagens cognitiva e afetiva. Considerando a classe social, a relação foi confirmada apenas para a imagem cognitiva e com natureza negativa, pois quanto maior a classe social menor a pontuação dada aos recursos naturais e culturais do destino. $\bigcirc$ país de origem confirmou-se em relação tanto à imagem cognitiva quanto à imagem afetiva.

Yacout e Hefny (2015) verificaram os dados demográficos referentes a idade e renda como significativos na formação da imagem cognitiva. Os aspectos demográficos, porém, não foram significativamente relacionados com a imagem afetiva. Segundo os autores, apesar de não ter sido verificado em seu estudo, é possível que a relação entre a imagem afetiva e os dados demográficos seja indireta por meio da imagem cognitiva.

A partir do exposto e tendo em vista os resultados conflitantes, formulou-se a seguinte hipótese:

Hipótese 10: As características sociodemográficas (sexo, faixa etária, classe social e escolaridade) influenciam significativamente a imagens cognitiva, afetiva e única.

\section{Motivações turísticas}

A motivação turística representa os porquês ou motivos de uma escolha específica, agindo como um gatilho que desencadeia todos os eventos envolvidos em uma viagem. Do ponto de vista cognitivo, motivação é uma temática complexa, ten- do em vista que a tomada de decisão real de um turista é consequência de uma ampla gama de fatores e ocorre em função da quantidade cada vez maior de informações (PARRINELLO, I 993).

Para Crompton (1979), a motivação é uma variável crítica, por ser a força impulsora para o viajante. $O$ autor identificou sete motivações sociopsicológicas e duas motivações culturais que influenciam a escolha de um destino. Como motivações sociopsicológicas têm-se: escape, exploração, autoavaliação, relaxamento, prestígio, regressão, aperfeiçoamento de relacionamentos de parentesco e interação social. Como motivações culturais: busca por novidade e educação, ou conhecimento. A ligação entre essas motivações e a imagem de destino está relacionada à forma como os indivíduos percebem o destino: sua percepção será mais positiva para aqueles atributos que correspondam aos benefícios buscados (SUÁREZ; JOSÉ, 20II). Desse modo, a motivação "representa uma predisposição, que o indivíduo desenvolve, de tentar conseguir satisfazer seus desejos pela aquisição de um produto, no caso o turístico" (CHAGAS, 2009).

Em relação à influência das motivações turísticas sobre a imagem de destino, o Quadro 4 apresenta uma síntese dos estudos que apresentaram hipóteses relacionadas e os resultados, confirmação ou não dessas hipóteses. Em todos os estudos, ao menos uma das dimensões foi significativa e todos verificaram a influência das motivações turísticas apenas sobre a imagem afetiva, com exceção dos estudos de Chagas, Marques Júnior e Duarte (2013), que relacionaram as motivações diretamente à imagem de destino. 
QUADRO 4 - Hipóteses de estudos relacionadas às motivações turísticas

\begin{tabular}{|c|c|c|}
\hline Referência & Hipótese & Resultado \\
\hline \multicolumn{3}{|c|}{ Motivações turísticas } \\
\hline $\begin{array}{l}\text { (MCCLEARY; } \\
\text { BALOGLU, 1999) }\end{array}$ & $\begin{array}{l}\text { As motivações psicossociais de turistas } \\
\text { influenciam significativamente suas } \\
\text { avaliações afetivas de destinos. }\end{array}$ & $\begin{array}{l}\text { Hipótese apenas moderadamente confirmada: apenas a } \\
\text { dimensão relaxamento/escape foi significativa. }\end{array}$ \\
\hline $\begin{array}{l}\text { (BEERLI; MARTÍN, } \\
\text { 2004) }\end{array}$ & $\begin{array}{l}\text { As motivações influenciam } \\
\text { significativamente o componente afetivo } \\
\text { da imagem percebida. }\end{array}$ & $\begin{array}{l}\text { Para turistas de primeira visita, as dimensões de relaxamento } \\
\text { e conhecimento foram significativas. Para turistas retorno, } \\
\text { a dimensão de conhecimento teve relação negativa com a } \\
\text { imagem afetiva. A hipótese foi moderadamente confirmada. }\end{array}$ \\
\hline $\begin{array}{l}\text { (SAN MARTÍN; } \\
\text { RODRÍGUEZ DEL } \\
\text { BOSQUE, 2008) }\end{array}$ & $\begin{array}{l}\text { A imagem afetiva de um destino turístico } \\
\text { é significativamente influenciada por } \\
\text { motivações psicológicas do turista. }\end{array}$ & Hipótese confirmada. \\
\hline $\begin{array}{l}\text { (CHAGAS; MARQUES } \\
\text { JÚNIOR; DUARTE, } \\
\text { 2013) }\end{array}$ & $\begin{array}{l}\text { A imagem do destino é diretamente } \\
\text { influenciada pela motivação do turista. }\end{array}$ & $\begin{array}{l}\text { Das quatro dimensões de motivações propostas pelos } \\
\text { autores, uma foi significativa (lazer, entretenimento, praia e } \\
\text { paisagens). Hipótese parcialmente confirmada. }\end{array}$ \\
\hline
\end{tabular}

Fonte: Dados da pesquisa

Mccleary e Baloglu (1999), apesar de terem avaliado a influência das motivações turísticas apenas sobre a imagem afetiva, constataram, a partir de uma matriz de correlação, que as motivações apresentaram uma relação significativa com as avaliações cognitivas. Tomando por base as considerações de Mccleary e Baloglu (1999), no modelo proposto a relação das motivações turísticas sobre as imagens cognitiva, afetiva e única foi incluída.

A partir do exposto, formulou-se a seguinte hipótese de pesquisa:

Hipótese 9: As motivações turísticas influenciam significativamente as imagens cognitiva, afetiva e única.

\section{Influência da imagem de destino sobre intenções comportamentais}

A imagem de destino desempenha importante papel para a fidelização do turista (ZHANG et al., 20I4). Segundo Bigné, Sánchez e Sánchez (200I), sua influência inicia-se na fase de escolha do destino, mas ela é também determinante para o comportamento pós-compra: na intenção de retornar ao destino ou reco- mendá-lo. Desse modo, a imagem de um destino turístico pode influenciar tanto a tomada de decisões pré-viagem quanto a avaliação pós-viagem, afetando desde a escolha de um destino até a satisfação geral com a experiência no destino (SMITH et al., 2015).

Essa influência da imagem de destino sobre as intenções comportamentais foi foco dos estudos de Chen e Tsai (2007), que, verificaram que quanto mais favorável a imagem de um destino maior a probabilidade de recomendação pelo turista e maior a probabilidade de retorno (BIGNE; SANCHEZ; SANCHEZ, 200I; CASTRO; MARTÍN ARMARIO; MARTÍN RUIZ, 2007; CHEN;TSAI, 2007; NISCO et al., 20I5).Trata-se do que Zhang et al. (20I4) denominam de "lealdade atitudinal", fazendo referência à expressão psicológica dos turistas a partir da intenção de revisitar um destino ou de recomendá-lo para outros.

O Quadro 5 apresenta, considerando os autores consultados, uma síntese dos estudos que apresentaram hipóteses relacionadas e os resultados, confirmação ou não dessas hipóteses. 


\section{QUADRO 5 - Hipóteses de estudos relacionadas à influência da imagem de destino sobre intenções comportamentais}

\begin{tabular}{|c|c|c|}
\hline Referência & Hipótese & Resultado \\
\hline \multicolumn{3}{|c|}{ Intenção comportamental - retorno / recomendação } \\
\hline \multirow{2}{*}{$\begin{array}{l}\text { (BIGNE; } \\
\text { SANCHEZ; } \\
\text { SANCHEZ, } \\
\text { 2001) }\end{array}$} & $\begin{array}{l}\text { Uma imagem mais favorável de um destino aumenta } \\
\text { a probabilidade de que o turista vai voltar no futuro. }\end{array}$ & \multirow{2}{*}{$\begin{array}{l}\text { Hipóteses confirmadas. A imagem determina se as } \\
\text { pessoas recomendam o destino e a intenção de } \\
\text { voltar. }\end{array}$} \\
\hline & $\begin{array}{l}\text { Uma imagem mais favorável de um destino aumenta } \\
\text { a probabilidade de que o turista vai recomendá-lo. }\end{array}$ & \\
\hline $\begin{array}{l}\text { (CHEN; TSAI, } \\
2007)\end{array}$ & $\begin{array}{l}\text { Quanto mais favorável a imagem do destino mais } \\
\text { positiva a intenção comportamental. }\end{array}$ & $\begin{array}{l}\text { Hipótese confirmada. A imagem de destino tem um } \\
\text { efeito significativamente positivo sobre as intenções } \\
\text { comportamentais. }\end{array}$ \\
\hline \multirow{2}{*}{$\begin{array}{l}\text { (QU; KIM; IM, } \\
\text { 2011) }\end{array}$} & $\begin{array}{l}\text { A percepção da imagem global media as relações } \\
\text { entre as imagens componentes (cognitiva, afetiva } \\
\text { e única) e a intenção do visitante para revisitar o } \\
\text { destino. }\end{array}$ & \multirow{2}{*}{$\begin{array}{l}\text { Os resultados apoiaram o papel mediador da imagem } \\
\text { global. }\end{array}$} \\
\hline & $\begin{array}{l}\text { A percepção da imagem global media as relações } \\
\text { entre as imagens componentes (cognitiva, afetiva e } \\
\text { única) e a intenção do visitante para recomendar o } \\
\text { destino para outros. }\end{array}$ & \\
\hline \multirow{2}{*}{$\begin{array}{l}\text { (NISCO et al., } \\
2015)\end{array}$} & $\begin{array}{l}\text { O componente afetivo da imagem geral de um país } \\
\text { formado como resultado da experiência de viagem } \\
\text { tem uma influência positiva sobre as intenções de } \\
\text { visitar novamente e boca a boca positivo. }\end{array}$ & Hipótese confirmada. \\
\hline & $\begin{array}{l}\text { A imagem de destino formada como resultado da } \\
\text { experiência de viagem tem uma influência positiva } \\
\text { sobre as intenções de visitar novamente e boca a } \\
\text { boca positivo. }\end{array}$ & Hipótese confirmada. \\
\hline
\end{tabular}

Fonte: Dados da pesquisa

Conforme apresentado no Quadro 5, todas as hipóteses relacionadas à influência da imagem de destino sobre intenções comportamentais para retorno e recomendação do destino visitado foram confirmadas, inclusive o papel mediador da imagem global entre suas dimensões e essas intenções comportamentais (QU; KIM; IM, 20I I). Zhang et al. (20I4), ao realizarem uma meta-análise a partir de 66 artigos publicados, verificaram que de todas as dimensões da imagem de destino (no caso, global, cognitiva e afetiva), a imagem global teve maior impacto na fidelização do turista. Qu, Kim e Im, (20II), após avaliarem a imagem global como mediadora entre as imagens cognitiva, afetiva e única e as intenções comportamentais, verificaram, comparativamente, um modelo concorrente ao seu, no qual as dimensões da imagem de destino teriam efeitos diretos sobre as intenções comportamentais, sem a intermediação da imagem global. Apesar de também confirmado, optaram pelo modelo mais parcimonioso com o papel mediador da imagem global. Como afirmado por Chen e Tsai (2007), os turistas utilizam a imagem percebida de um destino como parâmetro para formar expectativas antes da visita e compará-los com os resultados da experiência de viagem.

Diante do exposto, elaborou-se a seguinte hipótese de pesquisa:

Hipótese I I: A imagem global influencia positivamente as intenções comportamentais (para retorno e recomendação) dos visitantes. 


\section{Formação e influência da imagem de destino: modelo proposto}

Foram apresentadas até aqui, bases teóricas para cada uma das relações hipotéticas propostas no modelo a seguir (Figura 4): entre as dimensões da imagem de destino, seus antecedentes (familiaridade, características sociodemográficas e motivações) e entre a imagem global e intenções comportamentais (retorno e recomendação).

O modelo está também em acordo com o modelo teórico para o conceito de imagem de destino proposto por Gallarza, Saura e García (2002) que identificam quatro características desta dimensão: natureza complexa, natureza múltipla, natureza relativística e natureza dinâmica. A natureza complexa está relacionada às concepções quanto aos componentes que formam a imagem geral de um destino (cognitivo, cognitivo-afetivo) ou, mesmo, em relação à sua concepção: se decorre de uma impressão coletiva ou de impressões pessoais. A natureza múltipla diz respeito à multiplicidade de fatores ou variáveis que compõem uma imagem de destino. Não há, efetivamente, consenso quanto à convicção de que uma imagem deve ser medida a partir de atributos ou a partir de uma visão mais holística ou geral.A natureza relativística, por sua vez, está relacionada ao envolvimento simultâneo de uma avaliação subjetiva, por estar relacionada à interio-

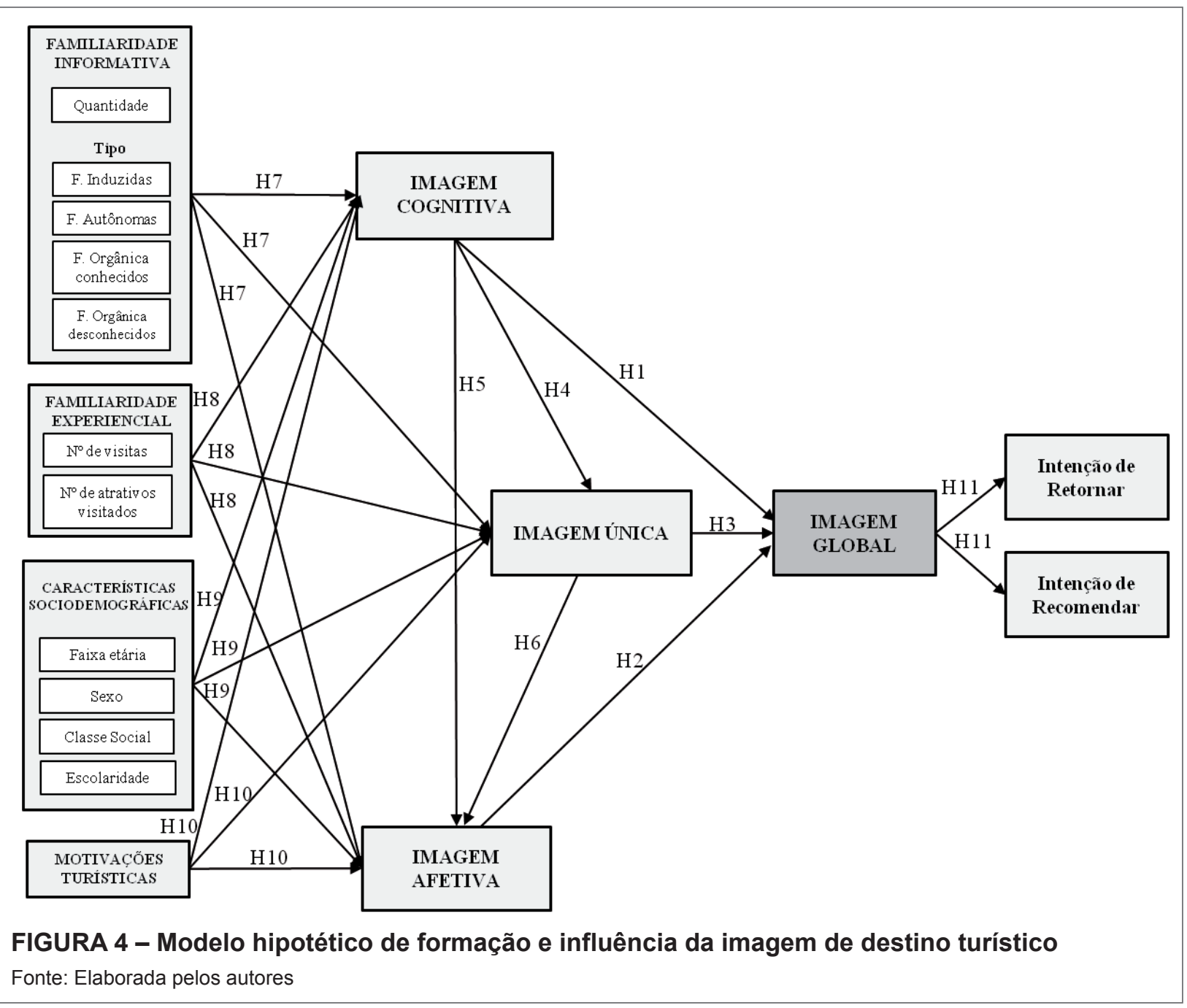


rização de algumas percepções e, de uma avaliação comparativa em relação a vários objetos. Por fim, a imagem de destino apresenta uma natureza dinâmica, ou seja, não estática, em função, essencialmente, de dois fatores: o tempo e o espaço. Envolve desde a influência da localização geográfica dos indivíduos em relação ao destino até a visão processual (tempo) da formação da imagem (GALLARZA; SAURA; GARCÍA, 2002).

O modelo tridimensional (bipolar) proposto por Echtner e Ritchie (I99I), conforme Figura 5, permite uma visualização de pelo menos três ângulos dessas características da imagem de destino: a natureza complexa, múltipla e relativística. $\mathrm{Na}$ vertical (funcional-psicológico), relacionando-se à natureza complexa da imagem, compreende que na avaliação da imagem de um destino contemplam-se desde elementos mais funcionais e racionais (cognitivo) até elementos mais abstratos (psicológicos) e emocionais (afetivo). Na horizontal (atributo-holístico), relacionando-se à natureza múltipla da imagem, concebe que a imagem de um destino pode ser mensurada a partir da avaliação de atributos específicos ou de uma visão mais geral (holística). $\mathrm{Na}$ diagonal (comum-único), relacionando-se à natureza relativística da imagem, entende que as características de um destino (sejam elas funcionais, psicológicas, específicas ou holísticas) podem ser analisadas comparativamente com outros destinos, sendo denominadas "comuns" ou "de valor único". A natureza dinâmica poderia ser verificada, nesse contexto, a partir de um estudo longitudinal, por exemplo.

No modelo proposto neste artigo ( $\mathrm{Fi}-$ gura 4), a imagem de destino é analisada como sendo composta por quatro dimensões: cognitiva, afetiva, única e global. Essa multiplicidade de dimensões ou componentes da imagem de destino reflete sua

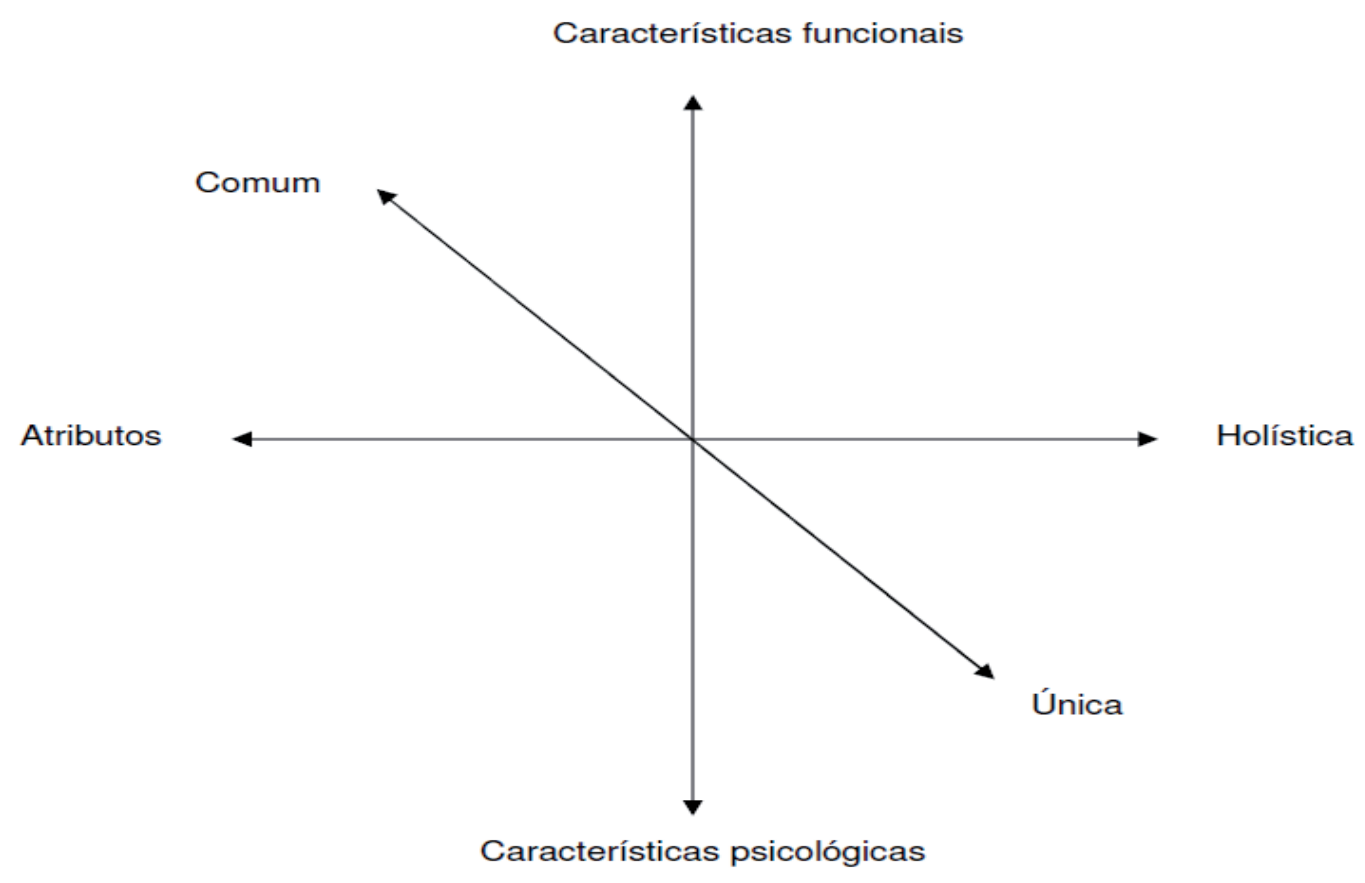

FIGURA 5 - Modelo tridimensional proposto por Echtner e Ritchie (1991)

Fonte: Adaptada de Echtner e Ritchie (1991) 
natureza complexa, bem como sua natureza relativística com a inclusão da imagem única que é operacionalizada a partir de análises comparativas entre destinos turísticos. Cada uma dessas dimensões é formada por variados fatores ou atributos, o que corresponde a essa natureza múltipla da imagem.

\section{Considerações finais}

O modelo proposto neste estudo, resultante da compilação das onze hipóteses apresentadas e discutidas, retrata a complexidade do construto imagem de destino tanto em função dos múltiplos fatores que o compõe, quanto em função do número de relações previstas. Essas relações apresentam-se não apenas como diretas, mas é possível verificar as influências indiretas a partir dos papéis mediadores das dimensões.

Este estudo teve por objetivo analisar modelos de formação da imagem de destino e sua influência sobre intenções comportamentais para retorno e recomendação visando a proposição de um modelo único de formação e influência da imagem de destino. Foi realizada uma revisão bibliográfica para embasar as relações propostas. Os estudos principais que sustentaram o modelo hipotético desta pesquisa foram os realizados por Mccleary e Baloglu (1999), Beerli e Martín (2004) e Qu, Kim e Im (20l I).

Mccleary e Baloglu (1999) trouxeram como contribuições principais para o modelo proposto as fontes de informação so- bre quantidade e tipos (familiaridade informativa), características sociodemográficas (idade e educação) e motivações como antecedentes das dimensões (cognitiva e afetiva) da imagem de destino e suas relações de interdependência também com outra dimensão, a imagem global. Os estudos de Beerli e Martín (2004) incluíram a experiência real com o destino (familiaridade experiencial), considerando tanto o número de visitas anteriores ao destino quanto o de atrativos turísticos visitados. A principal contribuição da pesquisa de Qu, Kim e Im (20l I) foi a inclusão da dimensão imagem única e da avaliação da influência da imagem global sobre intenções comportamentais para retorno e recomendação.

O estudo traz significativas contribuições para o escopo da temática imagem de destino, na medida em que provê uma discussão de modelos de formação da imagem de destino, além da compilação de um único modelo englobando quatro dimensões da imagem de destino (cognitiva, afetiva, única e global), a inter-relação entre essas dimensões, seus antecedentes, bem como sua influência sobre intenções comportamentais, permitindo uma visão mais ampla quanto à complexidade da temática. Além da compilação de um modelo mais dilatado, o estudo trouxe contribuições inovadoras a partir da previsão de relações ainda não testadas. Como sugestão para trabalhos futuros, recomenda-se o teste empírico para validação do modelo. 


\section{REFERÊNCIAS}

AHMED, Z. U. The influence of the components of a state's tourist image on product positioning strategy. Tourism Management, I99I.v. I2, n. 4, p. 33I-340.

ANKOMAH, P. K.; CROMPTON, J. L. Tourism Cognitive Distance: a set of research ProDositions. Annals of Tourism Research, 1992. v. 19, p. 323-342.

AWASTHY, D.; BANERJEE, A.; BANERJEE, B. Understanding the role of prior product knowledge to information search. Asia Pacific Journal of Marketing and Logistics, 30 mar. 20।2. v. 24, n. 2, p. 257-287.

BALOGLU, S. Image variations of Turkey by familiarity index: informational and experiential dimensions. Tourism Management, abr. 200I.v. 22, n. 2, p. 127-I33.

BEERLI, A.; MARTÍN, J. D. Factors influencing destination image. Annals of Tourism Research, jul. 2004. v. 3I, n. 3, p. 657-68I.

BIGNE, J. E.; SANCHEZ, M. I.; SANCHEZ, J. Tourism image, evaluation variables and after purchase behaviour: inter-relationship. Tourism Management, 200I.v. 22, n. 6, p. 607-616.

CASTRO, C. B.; MARTÍN ARMARIO, E.; MARTÍN RUIZ, D. The influence of market heterogeneity on the relationship between a destination's image and tourists' future behaviour. Tourism Management, fev. 2007. v. 28, n. I, p. 175-187.

CHAGAS, M. M. DAS. Formação da Imagem de Destinos Turísticos: uma discussão dos principais modelos internacionais. Caderno Virtual de Turismo, 2 jun. 2009. v. 9, n. I. Disponível em: <http://www.ivt.coppe.ufrj.br/caderno/index.php?journal=cader- no\&page $=$ article\&op=view\&path\%5B\%5D=333>. Acesso em: 18 out. 2015.

CHAGAS, M. M. DAS; MARQUES JÚNIOR, S.; DUARTE,A. C. F.Análise do processo de formação da imagem de destinos turísticos de sol e praia: um estudo em Canoa Quebrada/CE. Revista Brasileira de Pesquisa em Turismo, 12 dez. 20I3. v. 7, n. 3, p. 456.

CHANDRALAL, L.;VALENZUELA, F.R. Exploring Memorable Tourism Experiences: Antecedents and Behavioural Outcomes. Journal of Economics, Business and Management, 20I3. p. I77-I8I.

CHEN, C.-F.; TSAI, D. How destination image and evaluative factors affect behavioral intentions? Tourism Management, ago. 2007. v. 28, n. 4, p. III5-II 22.

CHERIFI, B. et al. Destination images of non-visitors. Annals of Tourism Research, nov. 20I4. v. 49, p. 190-202.

CHON, K.-S. Tourism destination image modification process: Marketing implications. Tourism Management, I99I. v. I2, n. I, p. 68-72.

CROMPTON, J. L. Motivations for pleasure vacation. Annals of Tourism Research, dez. 1979. v. 6, n. 4, p. 408-424.

DICHTER, E. What's In An Image. Journal of Consumer Marketing, jan. I985. v. 2, n. I, p. 75-8I.

ECHTNER, C. M.; RITCHIE, J. B. The meaning and measurement of destination image. Journal of tourism studies, 199I. v. 2, n. 2 , p. 2-I2.

GALLARZA, M. G.; SAURA, I. G.; GARCÍA, H. C. Destination image: towards a conceptual framework. Annals of Tourism Research, 2002. v. 29, n. I, p. 56-78.
GÂNDARA, J. M. G. A Imagem dos Destinos Turísticos Urbanos. Revista Eletrônica de Turismo Cultural, 2008. v. Número Especial, p. I-22.

GARTNER, W. C. Image Formation Process. Journal of Travel \& Tourism Marketing, 9 fev. 1994. v. 2, n. 2-3, p. 191-216.

HALLMANN, K.; ZEHRER, A.; MÜLLER, S. Perceived Destination Image An Image Model for a Winter Sports Destination and Its Effect on Intention to Revisit. Journal of Travel Research, I jan. 2015. v. 54, n. I, p. 94-106.

JACOBSEN, J. K. S.; MUNAR, A. M. Tourist information search and destination choice in a digital age. Tourism Management Perspectives, jan. 20I2. v. I, p. 39-47.

KIM, J.-H. The antecedents of memorable tourism experiences: The development of a scale to measure the destination attributes associated with memorable experiences. Tourism Management, out. 20I4. v. 44, p. 34-45.

KOTLER, P. et al. Marketing de lugares: como conquistar crescimento de longo prazo na América Latina e no Caribe. São Paulo: Prentice Hall, 2006.

LLODRÀ-RIERA, I. et al. A multidimensional analysis of the information sources construct and its relevance for destination image formation. Tourism Management, jun. 2015. v. 48, p. 319-328. MARIUSSEN, A.; IBENFELDT, $C$. VON;VESPESTAD, M. K. The typology and role of online information sources in destination image formation: an eye-tracking study. The International Journal of Digital Accounting Research, 20I4. v. |4, p. |4I-I64. MCCLEARY, K. W.; BALOGLU, S. 
A model of destination image formation. Annals of Tourism Research, 1999. v. 26, n. 4, p. 868-897.

MOURA, F. T.; GNOTH, J.; DEANS,

K. R. Localizing Cultural Values on Tourism Destination Websites The Effects on Users' Willingness to Travel and Destination Image. Journal of Travel Research, I jul. 2015. v. 54, n. 4, p. 528-542.

NISCO,A. D. et al. Tourism satisfaction effect on general country image, destination image, and post-visit intentions. Journal of Vacation Marketing, I abr. 20I5. p. I-I3.

PARRINELLO, G. L. Motivation and anticipation in post-industrial tourism. Annals of Tourism Research, jan. 1993. v. 20, n. 2, p. 233-249.

PETROCCHI, M. Marketing para destinos turísticos. São Paulo: Futura, 2004.
PHELPS, A. Holiday destination image-The problem of assessment: An example developed in Menorca. Tourism Management, 1986. v. 7, n. 3, p. 168-180.

PIKE, S. Destination image analysis-a review of 142 papers from 1973 to 2000. Tourism management, 2002. v. 23, n. 5, p. 54I-549.

QU, H.; KIM, L. H.; IM, H. H. A model of destination branding: Integrating the concepts of the branding and destination image. Tourism Management, jun. 20I I. v. 32, n. 3, p. 465-476.

SAN MARTÍN, H.; RODRÍGUEZ DEL BOSQUE, I. A. Exploring the cognitive-affective nature of destination image and the role of psychological factors in its formation. Tourism Management, abr. 2008. v. 29, n. 2, p. 263-277.

SMITH, W.W. et al. Tracking destination image across the trip expe- rience with smartphone technology. Tourism Management, jun. 20 I5. v. 48, p. II3-I 22.

SUÁREZ,A.; JOSÉ, M. The Formation of the Tourist Image from the Traveler's Cultural Distance Perspective. Estudios y Perspectivas en Turismo, dez. 20I I.v. 20, n. 6, p. 1237-I 257.

TASCI,A. D.A.; GARTNER,W. C. Destination Image and Its Functional Relationships. Journal of Travel Research, 5 jan. 2007. v. 45, n. 4, p. 4 I 3-425.

YACOUT, O.M.; HEFNY, L. I.Use of Hofstede's cultural dimensions, demographics, and information sources as antecedents to cognitive and affective destination image for Egypt. Journal of Vacation Marketing, I jan. 20I5. v. 2I, n. I, p. 37-52.

ZHANG, $\mathrm{H}$. et al. Destination image and tourist loyalty: A meta-analysis. Tourism Management, fev. 20I4. v. 40, p. 21 3-223. 